\title{
Gestão e processos de trabalho nos Centros de Testagem e Aconselhamento de Porto Alegre-RS na perspectiva de seus aconselhadores
}

\author{
I ${ }^{1}$ Cristina Beatriz Haag, ${ }^{2}$ Tonantzin Ribeiro Gonçalves, \\ ${ }^{3}$ Nêmora Tregnago Barcellos I
}

Resumo: O estudo objetivou avaliar o trabalho nos Centros de Testagem e Aconselhamento (CTAs) do município de Porto Alegre-RS na perspectiva de seus aconselhadores. Tratou-se de pesquisa qualitativa envolvendo a realização de seis grupos focais com 13 aconselhadoras dos três CTAs do município. Os relatos foram submetidos à análise de conteúdo qualitativa, resultando na categoria temática central Conjugaçôes entre gestão e processos de trabalho nos CTAs. Na visão das aconselhadoras, os serviços são essenciais para o diagnóstico e a prevenção em HIV/Aids e contribuem muito para a efetivação dos atendimentos nessa área. Contudo, os serviços estariam vivendo uma crise quanto ao seu papel, em função da expansão do aconselhamento e da testagem anti-HIV para a rede básica de saúde. Essas mudanças trouxeram angústias e incertezas, principalmente pela falta de diálogo com as esferas gestoras e pela ausência de diretrizes claras para o trabalho no contexto das novas políticas nacionais. Os achados também evidenciaram a preocupação com a qualidade e a forma como o aconselhamento será realizado na Atenção Básica, bem como a necessidade de mais profissionais para o atendimento em HIV/Aids e de consultas com especialidades médicas. Acredita-se que estratégias de gestão participativa poderiam contribuir no redirecionamento da atuação dos CTAs, fortalecendo o matriciamento da testagem e do aconselhamento em HIV e reforçando os CTAs na atenção de maior complexidade e como formadores de recursos humanos na área.

> Palavras-chave: aconselhamento; HIVIAids; CTA; avaliação em saúde.

\author{
1 Psicóloga, sanitarista, mestre \\ em Saúde Coletiva pelo \\ Programa de Pós Graduação em \\ Saúde Coletiva da Universidade \\ do Vale do Rio dos Sinos \\ (Unisinos). Endereço eletrônico: \\ cbhaag@gmail.com \\ 2 Psicóloga, doutora em \\ Psicologia (UFRGS) e professora \\ do Programa de Pós Graduação \\ em Saúde Coletiva da \\ UNISINOS. Endereço eletrônico: \\ tonanrib@yahoo.com.br \\ ${ }^{3}$ Médica clínica (Secretaria \\ Estadual da Saúde/RS), doutora \\ em Clínica Médica (UFRGS) \\ e professora do PPG em \\ Saúde Coletiva da UNISINOS. \\ Endereço eletrônico: \\ nemoratb@gmail.com
}




\section{Introdução}

As políticas brasileiras de prevenção e tratamento em DST/HIV/Aids, articuladas com movimentos da sociedade civil, têm gerado grande impacto no controle da epidemia e na redução de mortes causadas por ela, recebendo reconhecimento internacional. Uma das respostas brasileiras à epidemia de DST/HIV/Aids foi a criação, em 1988, seguindo tendências internacionais, dos Centros de Testagem e Aconselhamento (CTA), inicialmente denominados Centros de Orientação e Apoio Sorológico (COAS). O primeiro serviço foi implantado na cidade de Porto Alegre/RS. No Brasil, os CTAs primam por oferecer testagem gratuita, confidencial e algumas vezes anônima para HIV e sífilis, incorporando, nos últimos anos, o diagnóstico das hepatites $\mathrm{B}$ e C. Atuam a partir de referenciais da educação em saúde, visando à redução do risco e das vulnerabilidades (MINAYO et al., 1999; BRASIL, 2010). Assim, a modalidade de aconselhamento constitui uma importante estratégia no combate ao HIV/Aids no Brasil, tanto pelo baixo custo de sua aplicação, quanto pelo seu potencial de efetividade.

No CTA, os usuários passam por uma sessão de aconselhamento individual ou coletiva. Os aconselhadores atuam informando e esclarecendo dúvidas sobre DST, HIV/Aids e hepatites virais, além de fornecer apoio na avaliação dos riscos de exposição de cada pessoa e das alternativas para prevenção (BRASIL, 2010; MONDINI; ESCOBAR, 2008). Além dos aconselhamentos, os profissionais do CTA devem realizar palestras e atividades intra e extramuros (em escolas e empresas) e disponibilizar equipamentos de prevenção, como camisinhas masculinas e femininas, gel lubrificante e kits de redução de danos para pessoas que usam drogas (BRASIL, 2010).

Apesar dos esforços, os números da infecção pelo HIV/Aids no Brasil ainda causam preocupação. Até junho de 2011, contabilizavam-se 608.230 casos de Aids registrados desde 1980, com uma incidência de 17,9 casos a cada 100 mil habitantes (BRASIL, 2011a). A faixa etária mais atingida pela doença é a de 25 a 49 anos de idade, e a forma de transmissão mais frequente, acima dos 13 anos, é a relação sexual heterossexual, correspondendo a $83,1 \%$ dos casos entre mulheres e $42,4 \%$ entre homens. Considerando as regiōes do país, nos últimos dez anos, a taxa de incidência caiu no Sudeste e aumentou na região Sul (BRASIL, 2011a). O Rio Grande do Sul (RS) apresenta as mais altas taxas de incidência desde 2002, atualmente com 37,6 novos casos de Aids a cada 100 mil habitantes (BRASIL, 
2011b). Segundo dados do Ministério da Saúde, em 2010, o município de Porto

Alegre está no primeiro lugar na incidência de Aids entre todas as capitais da federação e entre as cidades com mais de 50 mil habitantes, com 99,8 novos casos a cada 100 mil habitantes (BRASIL, 2011b).

Buscando fomentar novas estratégias de enfrentamento da epidemia, o Departamento de DST, Aids e Hepatites Virais, em parceria com Secretarias Estaduais e Municipais de Saúde, passou a propor, a partir de 2005, a ampliação do oferecimento da testagem anti-HIV para os serviços de Atenção Básica, ação que teve início na região Norte do país. Outra estratégia implementada foi a campanha Fique Sabendo, de estímulo à testagem precoce. Com isso, os CTAs foram fortalecidos enquanto serviços de retaguarda assistencial na capacitação para a realização da testagem e no aconselhamento na Atenção Básica.

Quanto às relações entre os CTAs e os demais serviços da rede de saúde, à interface com a gestão e à implementação das políticas de HIV/Aids, foram identificados poucos estudos. Minayo et al. (1999) avaliaram CTA da região Nordeste por meio de um estudo quali-quantitativo. Dentre seus achados, verificaram dificuldades de relacionamento com a rede de referência e contrarreferência das pessoas vivendo com HIV pela reduzida oferta de leitos hospitalares e da precariedade dos serviços ambulatoriais. No âmbito internacional, Kabbash et al. (2010) realizaram grupos focais com 16 aconselhadores para avaliar serviços de testagem e aconselhamento em HIV do Egito. Os achados dos autores apontaram demandas dos profissionais por melhor capacitação, definição específica de suas atribuições e funções, além de critérios mais claros para avaliar os resultados do seu trabalho, uma vez que ficavam restritos ao número de atendimentos e à percepção subjetiva de cada aconselhador.

Considerando essas lacunas, o presente estudo buscou avaliar os CTAs do município de Porto Alegre/RS na perspectiva de seus aconselhadores. Em particular, buscou-se enfocar as interrelaçôes entre gestão e processos de trabalho. Ao adotar a ótica do trabalhador em saúde, o estudo procura dar voz aos profissionais que atendem o usuário diariamente e que têm uma visão privilegiada quanto às dificuldades e qualidades do serviço (TANAKA; MELO, 2008). Entende-se que a valorização e o engajamento dos profissionais de saúde no Sistema Único de Saúde é peça chave da Política Nacional de Humanização à Saúde (BRASIL, 2004). Particularmente no âmbito dos CTAs, a perspectiva 
dos profissionais pode fornecer evidências importantes para o aprimoramento desses serviços e de sua interface com os demais serviços da rede (Atenção Básica, Serviços de Atendimento Especializados em HIV/Aids (SAE), Serviços de média complexidade e atendimento hospitalar).

\section{Método}

Trata-se de pesquisa qualitativa de caráter exploratório e descritivo sobre a avaliação do trabalho nos CTAs do município de Porto Alegre/RS e sobre o envolvimento desses serviços nas políticas públicas em HIV/Aids na perspectiva dos seus aconselhadores. O projeto de pesquisa foi aprovado pelo Comitê de Ética em Pesquisa da Universidade do Vale do Rio dos Sinos - Unisinos, protocolo 11/126.

Foram contatados os três CTAs da cidade, dois estaduais e um municipal, tendo sido convidadas a participar do estudo as 14 aconselhadoras desses serviços. Não houve recusas; apenas uma aconselhadora não pode participar, pois estava em período de licença-saúde, totalizando 13 participantes. Para a coleta de dados, foi utilizada a técnica de grupo focal, com questôes norteadoras sobre a avaliação do serviço de saúde na perspectiva das trabalhadoras. Em cada CTA foram realizados dois grupos focais, que tiveram entre quatro e cinco participantes, além da pesquisadora moderadora, também com experiência prévia de aconselhamento em HIV/Aids. Durante as sessões, a pesquisadora buscou encorajar as interações grupais para que se discutisse o tema proposto, solicitando, quando necessário, o aprofundamento de alguns aspectos para entender melhor os pontos de vista dos participantes (BARBOUR, 2009). Os encontros duraram aproximadamente duas horas e aconteceram em locais reservados disponíveis nos próprios serviços. Todos os grupos foram gravados em áudio para posterior transcrição.

No primeiro encontro com cada equipe, a pesquisadora apresentou sua experiência profissional, o projeto de pesquisa e seus objetivos. Em seguida, o Termo de Consentimento Livre e Esclarecido foi lido na presença de todas as aconselhadoras e assinado.

Os grupos focais discorreram sobre o tema "O Trabalho no CTA". Para estimular a espontaneidade das discussões, utilizou-se um roteiro simples com as seguintes questões: 1) Como é trabalhar no CTA? Como está sendo, neste momento, trabalhar no CTA?; 2) Quais as dificuldades encontradas na execução do trabalho?; 3) Quais os pontos positivos de trabalhar no CTA?. 
Os relatos dos grupos foram submetidos a análise de conteúdo em pesquisa qualitativa (BARDIN, 1977; OLABUENÁGA, 1996) visando investigar a avaliação do trabalho nos CTAs na perspectiva de seus aconselhadores. A matriz teórica que embasou as análises foi a Hermenêutica-Dialética proposta por Minayo (2002). A análise hermenêutica-dialética pretende compreender e dar sentido à linguagem como realidade construída e compartilhada pelos indivíduos em movimentos contraditórios e historicamente situados (MINAYO, 2002). Durante as análises, buscou-se identificar particularidades e semelhanças nas perspectivas das aconselhadoras dos diferentes CTAs, privilegiando-se conteúdos manifestos e implícitos relativos à avaliação dos serviços, em detrimento da análise dos processos grupais específicos ao funcionamento de cada equipe. Após diversas leituras do material, identificaram-se categorias temáticas que foram utilizadas para a discussão final dos relatos. Para fins de validação da análise realizada, o texto interpretativo provisório foi enviado para apreciação das aconselhadoras participantes da pesquisa, contemplando-se suas sugestôes na elaboração do relato final.

\section{Resultados e discussão}

As 13 profissionais exercendo a função de aconselhador de CTA em Porto Alegre eram mulheres, casadas e tinham idade média de 47 anos. Todas possuíam curso superior e, com exceção de uma, também realizaram pós-graduação. A maior parte era graduada em Psicologia (6), seguida por Serviço Social (5), Enfermagem (2) e Nutrição (1).

A partir da leitura exaustiva do material transcrito e com base nas questões norteadoras dos grupos focais, as análises sobre a avaliação do trabalho nos CTAs na perspectiva das aconselhadoras resultaram em uma categoria temática central: Conjugaçôes entre gestão e processos de trabalho nos CTAs. A identificação dos relatos incluiu uma designação referente ao grupo (G1, G2 ou G3) e outra relativa a cada aconselhadora (i.e., de P1G1 a P13G3).

A fim de contemplar com maior clareza os vários aspectos referidos pelas aconselhadoras, a categoria central foi dividida em cinco subcategorias: Desafios do matriciamento e do teste rápido na Atenção Básica; Crise do papel dos CTAs no cenário atual e possibilidades para o futuro; Entraves da rede de encaminhamentos; Cenários político-administrativos e o trabalho nos CTAs; e Reconhecimento do trabalho nos CTAs pela gestão. 


\section{Conjugações entre gestão e processos de trabalho nos CTAs}

As aconselhadoras dos três CTAs destacaram diversos aspectos que associavam a gestão dos serviços de saúde no âmbito estadual e as políticas públicas locais e nacionais aos seus processos de trabalho. De modo geral, as trabalhadoras partilhavam uma sensação de falta de controle quanto a alguns aspectos do seu trabalho. Por outro lado, buscaram, em diversos momentos, reafirmar a importância da sua atuação profissional e pontuar as potencialidades do CTA no cenário atual.

\section{Desafios do matriciamento e do teste rápido na atenção básica}

Segundo as aconselhadoras, os CTAs de Porto Alegre estavam vivendo o processo de descentralização da testagem anti-HIV, que passaria a ser ofertado nas UBS, por meio de um processo de matriciamento e capacitação dos trabalhadores da rede básica. A ampliação do diagnóstico de HIV/Aids para a rede básica está sendo proposta nacionalmente em virtude do aumento do número de casos da doença na população e da necessidade de diagnósticos mais precoces para melhor cuidado e higidez dos usuários (BRASIL, 2005).

Tendo em vista o avanço da epidemia de HIV/Aids, as aconselhadoras dos três CTAs concordaram que a testagem também devia ser oferecida nas UBS e que os pacientes em boas condições de saúde, se assim desejassem, fossem acompanhados por esses serviços. Todavia, fizeram várias ponderações sobre a efetivação do processo de matriciamento. Primeiro, avaliaram que nem todos os profissionais teriam o perfil de aconselhador, e que seria importante cada UBS identificar aqueles que tivessem as características necessárias e que desejassem desempenhar essa atividade. Em segundo lugar, argumentaram que as UBS já teriam muito trabalho e que se deveria ter cuidado especial para que a testagem anti-HIV e o aconselhamento não sobrecarregasse essas equipes ou que fosse adotada de modo mecânico, como mais um tarefa a ser cumprida:

Para ser aconselhador tem que ter perfil e não pode ter sobrecarga de trabalho como em algumas UBS. Eles não vão dar conta. É mais uma demanda (P12G3).

As aconselhadoras destacaram que os CTAs e os SAE deveriam continuar ofertando seus serviços, formando uma retaguarda para casos mais complexos, como o apoio matricial à rede, e atendendo os pacientes que preferissem atendimento no local por questôes de sigilo, por exemplo: 
As pessoas não querem que na sua comunidade saibam que ela tem HIV. Acompanhan-

do o PSF, vimos um caso. Tinha um paciente e o agente comunitário sabia que ele tinha HIV e encaminhou para cá. Aí, fomos ver, e ela já tinha prontuário há horas (P8G2).

As mesmas preocupações das aconselhadoras do presente estudo sobre a realização do aconselhamento nas UBS também foram abordadas em um estudo com profissionais de saúde da rede básica de São Paulo (SILVA, 2011), no qual profissionais relataram falta de tempo para uma escuta de qualidade em função da exigência de grande número de atendimentos diários. Entendese que essa demanda provém da escassez de recursos humanos, dentre outros aspectos, o que desconfigura o projeto de atenção e impõe a precarização da atenção em saúde. O processo diagnóstico de HIV deveria colocar o profissional na posição de escuta, apoio, reflexão e encontro com o usuário. Porém, ao investigar a realização da testagem anti-HIV na rede básica, Silva (2011) apontou dificuldades dos profissionais em lidar com aspectos subjetivos e íntimos, envolvendo sexualidade, uso de drogas e conjugalidade. Assim, o foco no aconselhamento tende a ficar nos parâmetros biológicos e na solicitação de exames por queixas somáticas, fragmentando a atenção à saúde e distanciandose do sofrimento psíquico e social dos usuários.

$\mathrm{O}$ apoio matricial em saúde, recomendado nacionalmente para o enfrentamento do HIV, define-se como retaguarda especializada a equipes e profissionais na linha de frente (CAMPOS; DOMITTI, 2007). O apoio matricial prevê que os profissionais das UBS identifiquem a necessidade ou não do suporte técnico individual para cada usuário e que os apoiadores possuam conhecimento e perfil para agregar recursos e contribuir em intervenções mais resolutivas frente às questôes de saúde identificadas pelas equipes de referência. Conforme Campos e Domitti (2007), o apoio matricial teria como um de seus objetivos promover encontros, discussões e desacomodações entre os profissionais de referência, possibilitando a composição de projetos terapêuticos que abarquem outras visóes de mundo.

Diante disso, as preocupações das aconselhadoras são pertinentes, e o apoio matricial tem, de fato, o papel de problematizar aspectos técnicos e subjetivos do fazer em saúde. Contudo, entende-se ser necessário um espaço que amplie o diálogo entre as equipes dos CTAs, os trabalhadores das UBS e os gestores. Tal espaço propiciaria a identificação conjunta de necessidades e a discussão de soluções para 
que o aconselhamento aconteça de modo mais efetivo na atenção básica, respeitando o espaço de escuta e cuidado com o usuário e com suas escolhas de vida.

Os relatos das aconselhadoras da presente pesquisa também revelaram uma grande preocupação quanto ao perfil do profissional de saúde que terá a função de aconselhador nas UBS. Esse profissional deve ter curso superior ou técnico e estar capacitado para a função por meio de formação específica (BRASIL, 2010). Contudo, para além dos atributos técnicos de formação, são necessárias condições para uma escuta ativa e livre de preconceitos. Assim, pensa-se que os profissionais de saúde que oferecem o aconselhamento devem estar dispostos a esse encontro com o outro e preparados para lidar com desenvoltura com diferentes interfaces da sexualidade, da conjugalidade e do uso de drogas, por exemplo.

\section{Crise do papel dos CTAs no cenário atual e possibilidades para o futuro}

No presente estudo, as aconselhadoras de todos os CTAs referiram viver uma crise quanto ao papel desses serviços de porta de entrada no sistema de saúde, principalmente quanto à atenção em HIV e sífilis. Uma das causas dessa crise, segundo elas, seria a descentralização da testagem para a rede básica. Nesse contexto, as aconselhadoras tentavam reafirmar a missão dos CTAs enquanto serviços que promovem prevenção, diagnóstico e aconselhamento de boa qualidade, preocupando-se com o atendimento integral do usuário.

De fato, espera-se que os CTAs continuem exercendo o apoio matricial, na capacitação e assistência a casos mais complexos. Porém, as profissionais mencionaram não terem tido retorno dos gestores e da Política Nacional sobre seu futuro, o que criava angústia e incerteza, como se verifica nos relatos:

Em todos os CTAs o seu papel está em crise. A epidemia mudou e o papel do CTA também mudou. Precisa ainda do CTA? Eu acho que sim, como uma retaguarda (P1G1);

Somos um serviço dentro do programa do Ministério da Saúde e não temos notícias há um ano e meio sobre CTA (P8G2);

Olha, depende, pode chegar alguém e dizer: 'Desinfeta o CTA, não precisa mais. Vai acabar.' Ficamos à mercê. Já teve outras estruturas boas que acabaram (P5G2).

O diagnóstico precoce da infecção pelo HIV passou a assumir importância particular a partir do surgimento da terapia combinada altamente efetiva. Essa importância cresce significativamente como resultado de estudos que mostraram 
o impacto do controle da carga viral na redução da transmissão vertical

(CONNOR, 1994), ocupacional (CARDO, 1997) e mesmo sexual do HIV (ATTIA, 2009), adicionalmente ao já conhecido efeito na qualidade de vida e na longevidade dos portadores da infecção tratados.

A falta de diálogo e direcionamentos claros parece ter criado essa situação, que poderia ser encaminhada de modo mais efetivo incluindo-se os profissionais no planejamento das ações. Possivelmente, os CTAs vão continuar existindo, mas em um novo lugar, que prevê o apoio técnico às equipes e a retaguarda assistencial para o atendimento aos casos mais complexos, aspectos já vislumbrados pelas aconselhadoras. Ações como grupos de autocuidado, de adesão ao tratamento e de psicoterapia breve também devem continuar a ser oferecidas à população pelos CTAs, além da atuação em educação na Saúde, que os consolidaria na formação de recursos humanos na área HIV/Aids. Contemplando esses aspectos, os CTAs realizam ações importantes na rede do SUS. Por isso, é essencial que os gestores de todas as instâncias formalizem esse novo papel, auxiliem e incluam as equipes dos CTAs nesse processo.

\section{Entraves da rede de encaminhamentos}

As profissionais de todos os CTAs apontaram dificuldades de encaminhar os usuários para atendimento na rede de saúde, as quais se referiam, principalmente, à recente implantação de um novo sistema de marcação de consultas para todos os serviços de saúde de Porto Alegre. Embora os dois SAE municipais tivessem médicos e consultas disponíveis, os CTAs estaduais não conseguiam encaminhar a eles usuários moradores da capital por inacessibilidade ao sistema, que centraliza a marcação de consultas. Assim, esses serviços só conseguiam agendar consultas para os usuários recém-diagnosticados nos dois SAE estaduais, que vêm sofrendo, ao longo dos anos, com a restrição de seus quadros e que funcionavam muito além de sua capacidade, como mostra esse relato:

Os maiores gargalos são para atendimento para hepatite, tuberculose e até para HIV.

[...] Temos só dois clínicos que atendem HIV e eles têm 10 a 12 consultas agendadas (no turno). As agendas tão estranguladas (P3G1).

Já o CTA municipal, que deveria ter o encaminhamento facilitado por esse sistema informatizado, ainda não fora cadastrado e também não conseguia marcar as consultas para seus usuários. 
Além dos problemas com o atendimento em HIV/Aids, faltavam consultas para avaliação e atendimento psiquiátrico, para tratamento de dependência de álcool e outras drogas, além de outras especialidades, como gastroenterologia e pneumologia. Um serviço não tinha local de referência para casos de hepatite e tuberculose. Por outro lado, todos os CTAs tinham locais para encaminhamento em DST.

Outra questão trazida pelas aconselhadoras foi o encaminhamento de usuários oriundos do interior do estado. Se o resultado do teste for positivo e a cidade da pessoa possuir SAE, o CTA deve encaminhá-lo para lá. Todavia, alguns usuários preferem o atendimento no anonimato da capital:

O CTA faz diagnóstico para qualquer pessoa. Se tem HIV, hepatite e DST - para onde encaminha? O mais complicado é quando tem SAE no município da pessoa e ela não quer ficar (P8G2).

Os três CTAs ressaltaram a complexidade da situação clínica de alguns usuários vivendo com HIV/Aids na atualidade e as novas necessidades com que têm de lidar. Segundo as aconselhadoras, muitos apresentam graves efeitos colaterais depois de décadas de uso dos antirretrovirais, o que exige a mudança de medicamentos e o desenvolvimento de novos tratamentos, sem falar das demandas reprodutivas e por procedimentos estéticos para amenizar a lipodistrofia, por exemplo. Por outro lado, as aconselhadoras referiram facilidade em encaminhar as gestantes, para as quais já existem fluxos e locais predefinidos de assistência.

Sobre esses dados, Merhy e Franco (2003) já sinalizaram o "nó crítico" que tem constituído a atenção secundária em saúde. $\mathrm{O}$ equipamento hospitalar e a rede básica têm recebido atenção na reorganização da assistência à saúde por estarem um em contraponto ao outro. Já a atenção secundária não tem recebido tanta atenção, enfatizando-se as questóes da oferta e demanda de cuidados e consultas sem avançar na construção de um modelo mais interativo com os demais equipamentos. As participantes do presente estudo sublinharam tal aspecto ao comentar a superlotação das agendas e a falta de algumas redes formais de encaminhamento. Corroborando esses achados, Melchior et al. (2006) realizaram um estudo com todos os serviços públicos de saúde (336) que acompanhavam pacientes em terapia antirretroviral de sete estados brasileiros, representando diferentes situações epidemiológicas e institucionais. Os resultados apontaram uma quantidade exagerada de consultas por médico: 
quase $20 \%$ agendavam 16 ou mais consultas por turno. Isso seria reflexo do

número insuficiente de médicos, obrigando os profissionais a uma redução do tempo das consultas para atender à demanda.

Assim, parece que a integralidade e o "caminhar na rede" têm sido dificultados por gargalos na atenção secundária e na reduzida integração desta com outros recursos assistenciais. Para promover essa integração, é fundamental que linhas de cuidado sejam constituídas a partir da pactuação entre os diversos gestores dos serviços implicados em ofertar os recursos para o cuidado dos usuários (MERHY; FRANCO, 2003). Ainda, para que sejam possíveis fluxos entre unidades nos diferentes níveis de atenção, são necessários esforço e vontade política. A urgente integração e a pactuação de fluxos formais na rede é almejada pelos CTAs do estudo, que buscavam a promoção de saúde entre as pessoas vivendo com HIV/ Aids, o atendimento em tuberculose e hepatite, e também a contratação de mais médicos nos SAE estaduais.

Por fim, a implantação do sistema informatizado de encaminhamentos na rede municipal de Porto Alegre vem causando transtornos, inclusive colocando em risco a vida dos usuários do SUS. Isso representa uma falha grave na gestão pública municipal, tanto pela lentidão do processo de implantação, quanto pela inexistência de alternativas aos CTAs, durante o período de implantação do sistema, para o agendamento de consultas aos seus pacientes.

\section{Cenários politico-administrativos e o trabalho nos CTAs}

Os relatos das aconselhadoras revelaram a interferência de algumas questões político-administrativas no trabalho nos CTAs. Entre os centros estaduais, era necessária a vinculação direta ao Departamento de Ações em Saúde (DAS) e à Seção de Controle das DST/Aids, ambos entes da Secretaria Estadual da Saúde. Porém, esses CTAs foram lotados como estruturas hospitalares e eram administrados pelo Departamento de Coordenação dos Hospitais Estaduais (DCHE), relativamente afastado dos programas e ações específicas de saúde. Para as aconselhadoras, a situação se tornou ainda mais difícil, já que sentiam pouco respaldo para planejar e efetivar suas açōes, não conseguindo dialogar com instâncias técnicas da mesma área de atuação. Já o CTA municipal referiu dificuldades por estar vinculado a duas coordenaçôes, uma técnica e outra administrativa. O serviço estava tecnicamente vinculado à Política Municipal de 
Aids, mas, como se situava em um centro de saúde, a coordenação administrativa era da gerência do distrito daquela região.

As aconselhadoras de um dos CTAs referiram, mais enfaticamente, os reflexos de mudanças político-administrativas nos seus processos de trabalho. Para elas, após períodos eleitorais, os gestores costumam assumir cargos por indicação política e não técnica. Assim, quando uma nova gestão assume, tende, inicialmente, a tratar os servidores com desconfiança, como se fossem aliados da gestão anterior. A principal queixa dessas profissionais foi sobre a exclusão e a falta de escuta, pelos gestores, das demandas e propostas do serviço. Elas sentiam-se desvalorizadas e com pouco senso de controle sobre o próprio trabalho, pois suas opiniōes não eram consideradas.

Fica uma ideia para a nova gestão que todo mundo que está aqui é servidor da gestão anterior. Fica uma situação assim: 'Estamos dormindo com o inimigo'. [...] Não sabem, nem querem saber a história do nosso serviço (P10G3).

Sobre isso, Campos e Domitti (2007) defendem a construção de instâncias de mediação, espaços protegidos e contratos de trabalho que estabeleçam metas e critérios claros para avaliação do projeto de saúde oferecido à população. Para um bom funcionamento, o processo de trabalho deveria ser dialógico e interativo entre gestores, trabalhadores e usuários. Ainda, a Política Nacional de Humanização (PNH) (BRASIL, 2004) salienta a importância da gestão participativa nos diferentes níveis de atenção, pressupondo o diálogo entre os profissionais, entre estes a população, e entre os profissionais e a administração. Assim, deve-se buscar reconhecer, fortalecer e valorizar esse trabalhador com o compromisso da produção de saúde e de seu crescimento profissional.

Essas diretrizes corroboram o que foi debatido nos CTAs, que advogaram a maior participação na elaboração de mudanças programáticas e organizacionais dos serviços. Em especial, as participantes salientaram duas demandas: que os CTAs estivessem vinculados a coordenações próximas e ativas na área do HIV/ Aids para articularem ações conjuntas; e que gestores políticos alinhados à produção de saúde entendessem os funcionários como partidários do mesmo foco.

\section{Reconhecimento do trabalho nos CTAs pela gestão}

A falta de reconhecimento por parte da gestão foi citada unanimemente entre as trabalhadoras dos CTAs, de diferentes formas. Para elas, não existe 
reconhecimento pelos empregadores quanto à formação complementar, sendo que o salário permanecia o mesmo ainda que realizassem cursos de pós-graduação. A precarização das condições de trabalho, que incluía a baixa remuneração, a falta de visibilidade, os entraves na rede de encaminhamentos, as pressões por resultados numéricos dos atendimentos e a insuficiência de recursos humanos, contribuía para desestimular a busca por qualificações. Em contraposição a isso, as aconselhadoras salientaram a responsabilidade e a complexidade exigidas pela função que exerciam, que envolve lidar, diariamente, com situações de grande vulnerabilidade psíquica e social. Paradoxalmente, era do fato de tentarem auxiliar o usuário em situações tão dramáticas, que provinha grande parte da satisfação com o trabalho no CTA:

Encontra-se no fim do dia, exausta, atendeu casos complicados, e ganha menos que a ascensorista da Assembleia [Legislativa do Estado]. Essa é nossa figura de como é um trabalho desvalorizado. [...] Nos dá gratificação enorme, boa conversa com o paciente quando este entra demolido na sala e sai um pouco melhor. Mas a gente tem uma gratificação no fim do mês que paga também, e o trabalho é mal remunerado se comparar com outras categorias (P1G1).

A satisfação, a gratificação e o reconhecimento do trabalho vêm de atender bem aos usuários que procuram o serviço e de fazer parte de equipes que trabalham comprometidas e unidas. Em um dos CTAs, as trabalhadoras consideraram baixo o salário recebido quando comparado à remuneração de cargos semelhantes vinculados a instituições federais ou municipais. Ademais, a progressão salarial por tempo de serviço e a incorporação de outras bonificações foi citada como sendo mais lenta no nível estadual do que em instituições federais de saúde:

A gente tem que se alimentar dos pacientes, e tem épocas que se questiona se tá conseguindo fazer algo pelas pessoas, pois é muito limitado nosso poder de ação. Lugar sucateado, lugar não te valoriza. As ferramentas para ajudar os pacientes não são ideais. [...] Se quiser bom lugar de trabalho, boas condições de trabalho, bom salário, visibilidade, reconhecimento, tu não fica no Estado (P2G1).

Diante disso, entende-se que gerenciar serviços de saúde não é tarefa fácil. É necessário criar e instituir espaços para formulação de projetos e decisões coletivas. Para Campos (2007), os gestores em saúde deveriam mudar o modo como responsabilizam as equipes pelo trabalho. $\mathrm{O}$ autor sugere contratar com a equipe sua responsabilidade pela atenção de um conjunto de pessoas de um dado território ou sob sua alçada, estimulando o vínculo entre os pacientes e a equipe. Para o autor, essa abordagem traria mais resultados positivos do que a postura 
de cobrança quantitativa por produtividade, de procedimentos realizados e do cumprimento rígido do horário. Assim, embora muitas das mudanças propostas pela gestão sejam necessárias e estratégicas, a maneira impositiva e rígida de implementá-las, como citada por um CTA, não contribui para o bom andamento do trabalho e desvaloriza os trabalhadores. Novas propostas, metas e meios para obtê-las deveriam ser decididas em cogestão com os trabalhadores, engajando e corresponsabilizando as equipes, o que possivelmente geraria resultados mais satisfatórios e duradouros.

Por outro lado, considerou-se positiva a mudança recente no plano de carreira do servidor estadual do RS, que reduziu a carga horária para 30 horas semanais, com o mesmo salário, e ofereceu a opção de Dedicação Exclusiva, com 40 horas semanais, dobrando o valor dos vencimentos em quatro anos. Essa mudança vem ao encontro da valorização da jornada integral contemplada nas diretrizes da PNH (BRASIL, 2004). Entretanto, ainda são necessários ganhos reais destacando o empenho dos profissionais que buscam aprimorar seus estudos.

\section{Conclusões}

Os CTAs são serviços importantes de diagnóstico e prevenção em HIV/Aids e têm contribuído muito para a efetivação dos atendimentos na área ao longo dos anos. Esses serviços têm sido reconhecidos tanto pela comunidade como pelos profissionais de saúde da rede por oferecerem aconselhamento de qualidade, pela seriedade de suas ações, acesso facilitado, confiabilidade no resultado dos exames, pela garantia de sigilo e, ainda, como centros formadores de recursos humanos.

Atualmente, os CTAs estão vivendo uma crise quanto ao seu papel, pois o aconselhamento e a testagem anti-HIV estão sendo expandidos para a rede básica de saúde em todo o Brasil, sendo que os aconselhadores dos CTAs seriam os apoiadores matriciais. Porém, esse processo parece estar sendo vivido com angústia e incerteza por parte desses serviços no município de Porto Alegre/ RS. Há uma forte preocupação por parte desses profissionais de que as açôes de aconselhamento não sejam realizadas de modo adequado e efetivo nas UBS/ESF, pois essa seria apenas mais uma demanda na agenda já repleta de atividades dos locais e sem o acolhimento necessário ao usuário.

Nessa direção, caberia ao poder público, em suas diversas instâncias, esclarecer e debater com esses profissionais suas atividades e a nova configuração de suas 
funções no cenário atual da epidemia de HIV/Aids e de organização do SUS.

Para tanto, é necessário aproximar o diálogo com os CTAs e reconhecê-los como serviços de apoio matricial na expansão da testagem e aconselhamento, como referência assistencial de maior complexidade e como polos formadores de recursos humanos na área.

Os resultados do estudo apontaram, também, a necessidade de reforçar o quadro de profissionais para o atendimento de pessoas vivendo com HIV/ Aids e de criar fluxos formais para agendamento de consultas em HIV, hepatite, tuberculose e especialidades médicas como psiquiatra, pneumologia e gastroenterologia, contemplando toda a rede de serviços. Por fim, a PNH, na sua diretriz de gestão participativa e colegiados gestores com a presença dos trabalhadores, deve ser reforçada no cotidiano dos CTAs. ${ }^{1}$

\section{Referências}

ATTIA, S. et al. Sexual transmission of HIV according to viral load and antiretroviral therapy: systematic review and meta-analysis. AIDS, v.23, n.11, p.1397-1404, jul.2009.

BARBOUR, R. Grupos focais. Porto Alegre: Artmed, 2009.

BARDIN, L. Análise de conteúdo. São Paulo: Ediçōes 70, 1977.

BRASIL. Departamento de DST, Aids e Hepatites Virais. Aids no Brasil. Brasília: Ministério da Saúde, 2011a. Disponível em: <http://www.Aids.gov.br/pagina/Aids-nobrasil>. Acesso em: 24 jul. 2012.

. Departamento de DST, Aids e Hepatites Virais. Boletim Epidemiológico Aids e DST 2011. Brasília: Ministério da Saúde, 2011b. Disponível em: <http://www.Aids.gov.br/ publicacao/2011/boletim-epidemiologico-Aids-e-dst-2011>. Acesso em: 24 jul. 2012.

- Departamento de DST, Aids e Hepatites Virais. Diretrizes para Organização e Funcionamento dos CTAs do Brasil. Brasília: Ministério da Saúde, 2010.

. Programa Nacional de DST e Aids. Plano Estratégico do Programa Nacional de DST e Aids-2005. Brasília: Ministério da Saúde, 2005.

. Núcleo Técnico da Política Nacional de Humanização. HumanizaSUS: Política Nacional de Humanização: a humanização como eixo norteador das práticas de atenção e gestão em todas as instâncias do SUS. Brasília: Ministério da Saúde, 2004.

CAMPOS, G.W.S.; DOMITTI, A.C. Apoio matricial e equipe de referência: uma metodologia para gestão de trabalho interdisciplinar em saúde. Cadernos de Saúde Pública, Rio de Janeiro, v.23, n.2, p.399-407, fev.2007.

CAMPOS, R.O. A gestão: espaço de intervenção, análise e especificidades técnicas. In: CAMPOS, G. W.S.(Org.). Saúde Paideia. São Paulo: Hucitec, 2007.p. 122-149. 
CARDO, D.M. et al. A case-control study of HIV seroconversion in health care workers after percutaneous exposure. The New England Journal of Medicine, v.337, n. 21, p.1485-90, nov.1997. CONNOR, E.M. et al. Reduction of maternal-infant transmission of human immunodeficiency virus type 1 with zidovudine treatment. The New England Journal of Medicine, v.331, n.18, p.1173-80,nov.1994.

KABBASH, I.A. et al. Evaluation of HIV voluntary counselling and testing services in Egypt. Part 2: service providers' satisfaction. Eastern Mediterranean Health Journal,v.16, n.5, p.491-497, 2010.

MELCHIOR, R. et al. Avaliação da estrutura organizacional da assistência ambulatorial em HIV/Aids no Brasil. Revista de Saúde Pública, São Paulo, v.40, n.1, p.143-151, jan./fev. 2006.

MERHY, E.E.; FRANCO,T.B. Por uma Composição Técnica do Trabalho Centrada nas Tecnologias Leves e no Campo Relacional. Saúde em Debate. Rio de Janeiro, v.27, n.65, p.316-23,set./dez. 2003.

MINAYO, M.C.S. Hermenêutica-Dialética como Caminho do Pensamento Social. In: MINAYO, M.C.S.; DESLANDES, S.F. (Orgs.). Caminhos do pensamento: epistemologia e método. Rio de Janeiro: Fiocruz, 2002. p.83-108.

MINAYO, M.C.S. et al. Avaliação dos Centros de Orientação e Apoio Sorológico/CTA/ Coas da Região Nordeste do Brasil. Cadernos de Saúde Pública. Rio de Janeiro, v.15, n.2, p.355-367, abr./jun. 1999.

MONDINI, L.G.; ESCOBAR, L.R. Centro de Testagem e Aconselhamento (CTA): da Implantacão à Conquista do Espaco como Serviço de Referência em Acolhimento.In: LOUREIRO, R.P. et al (Orgs.). A maioridade da epidemia: vivências na trajetória dos 21 anos da Aids no Rio Grande do Sul. Porto Alegre: SES-RS, 2008. p.37-42.

OLABUENÁGA, J.I.R. Metodología de la Investigación Cualitativa. Bilbao: Universidad de Deusto, 1996.

SILVA, S.M. O diagnóstico anti-HIV no município do Rio de Janeiro: processos de cuidado em saúde. 2011. 198 f. Tese (Doutorado em Saúde Coletiva) - Programa de Pós-graduação em Saúde Coletiva, Universidade do Estado do Rio de Janeiro - UERJ, Rio de Janeiro, 2008.

TANAKA, O.; MELO, C. Avaliação de serviços e programas de saúde para a tomada de decisão. In: ROCHA, A.; CESAR, C. L. (Orgs.). Saúde Pública: bases conceituais. São Paulo: Atheneu, 2008. p.119-131.

\section{Nota}

${ }^{1}$ C. B. Haag elaborou o projeto de pesquisa, coletou e analisou os dados, escreveu o relatório final e o artigo. T. R. Gonçalves orientou a análise dos dados e a escrita do relatório final, participando da redação e da revisão da versão final do artigo. N.T. Barcellos orientou o projeto de pesquisa e o relatório final, participando da redação e revisão da versão final do artigo. 


\section{Abstract}

\section{Management and work processes in Voluntary}

Counseling and Testing Services in Porto Alegre city, Brazil, in the perspective of their counselors This qualitative study aimed to assess the work in Voluntary Counseling and Testing Services (VCT) in Porto Alegre, Brazil in the perspective of their counselors. It was conducted six focus groups with 13 counselors from the three VCT services in the city. Qualitative content analysis of the reports resulted in a central theme named Joining management and work processes in the VCT services. Counselors have emphasized that services are essential for HIV/AIDS diagnosis and prevention, and contributed significantly to effective healthcare. However, VCT services were facing a crisis regarding its role in the healthcare system since counseling and HIV testing activities were being extended as a responsibility of primary health care. These changes have brought anxiety and uncertainness among counselors, especially because the poor relationships with management levels and the lack of clear guidelines in the new policy context. Findings also pointed out counselors' concerns about the quality of counseling offered in the primary health care services, the lack of professionals to HIV/AIDS healthcare and the lack of medical specialist appointments. We endorsed that participatory management strategies could help to redirect VCT services activities, strength the matrix support testing and counseling for HIV and value these services as specialized healthcare providers and human resources reference for training in the area.

Key words: counseling; HIVIAids; VCT; health program assessment. 